\section{International Scientific Journal Theoretical \& Applied Science}

\author{
p-ISSN: 2308-4944 (print) e-ISSN: 2409-0085 (online) \\ Year: $2016 \quad$ Issue: 1 Volume: 33 \\ Published: $30.01 .2016 \quad \underline{\text { http://T-Science.org }}$
}

SECTION 9. Chemistry and chemical technology.

\section{Igor Viktorovich Goloperov}

Candidate of chemical sciences, Docent, Department of Chemical and Food Technology, Ukrainian Engineering and Pedagogical Academy, Ukraine goloperov_igor_viktorovich@ukr.net

Elena Aleksandrovna Belova Candidate of chemical sciences, Docent, Department of Chemical and Food Technology, Ukrainian Engineering and Pedagogical Academy, Ukraine

belovaalena@meta.ua

Aleksandr Nikolaevich Baklanov

Doctor of chemical sciences, Professor, Head of the Department of Occupational Health and Environmental Safety, Ukrainian Engineering and Pedagogical Academy, Ukraine

baklanov227@mail.ru

\title{
ULTRASOUND IN THE DETERMINATION CESIUM AND CESIUM-137 IN HIGHLY WATERS, BRINE AND SALT
}

\begin{abstract}
Studied the use of ultrasound in the determination of cesium in the highly mineralized waters, brines and salt: to convert the compounds of cesium in coprecipitated form and to intensify concentration in the coprecipitation of cupric ferrocyanide. Experimentally determine the factors intensifying exposure to ultrasound. Developed an express method of determination of cesium and cesium - 137. The detection limit of cesium - $2 \cdot 10$ $8 \%$, cesium-137 - 1 $10-13 \mathrm{Ku} / \mathrm{kg}$.

Key words: ultrasound, brines, cesium-137, coprecipitation, hexacyanoferrates divalent valence copper.

Language: Russian

Citation: Goloperov IV, Belova EA, Baklanov AN (2016) ULTRASOUND IN THE DETERMINATION CESIUM AND CESIUM-137 IN HIGHLY WATERS, BRINE AND SALT. ISJ Theoretical \& Applied Science, 01 (33): 64-68.

Soi: http://s-o-i.org/1.1/TAS-01-33-13 Doi: crossef http://dx.doi.org/10.15863/TAS.2016.01.33.13

\section{УЛЬТРАЗВУК В ОПРЕДЕЛЕНИИ ЦЕЗИЯ И ЦЕЗИЯ-137 В ВЫСОКОМИНЕРАЛИЗОВАННЫХ ВОДАХ, РАССОЛАХ И ПОВАРЕННОЙ СОЛИ}

Аннотация: Изучено применение ультразвука при определении цезия в высокоминерализованньх водах, рассолах и поваренной соли: для перевода соединений чезия в соосаждаемье формы и для интенсификации конщентрирования соосаждением на гексацианоферрате двухвалентной меди. Экспериментально установлены определяюшие факторы интенсифицирующего воздействия ультразвука. Разработана экспрессная методика определения цезия и иезия - 137. Предел обнаружения иезия - 2•10-8\%, цезия-137 - $1 \bullet 10-13 \mathrm{Ku} / к 2$.
\end{abstract}

Ключевые слова: ультразвук, рассол, цезий-137, гексацианоферрат двухвалентной меди.

Введение. Прямое определение цезия и цезия-137 в водах, рассолах и поваренной соли с использованием даже таких высокочувствительных методов анализа как пламенная атомно-абсорбционная спектрометрия и бета-спектрометрия не представляется возможным в ввиду их незначительного содержания в анализируемых объектах $[1,2]$.

Применение гамма-спектрометрии, обладающей экспрессностью и достаточной чувствительностью $\left(10^{-10} \mathrm{Ku} / к г\right)$, для определения цезия-137 ограничено высокой стоимостью аппаратуры и большой погрешностью анализа (более $50 \%$ ), в то время как при использовании радиохимического метода погрешность определения составляет всего лишь $10 \%[1,2]$.

В связи с чем, применяют предварительно е концентрирование, в качестве которого наиболее целесообразно использование сорбции или соосаждения [3, 4]. 
Применение сорбции на синтетических ионитах требует значительного количества ионитов 7-10 г на 1 дм ${ }^{3}$, что вызывает необходимость во избежание самопоглощения и саморассеяния бета-излуче-ния при определении цезия-137, использовать дополнительное выделение цезия-137 на носителе -двойной соли иодидов сурьмы и цезия, что значительно усложняет анализ и делает невозможным определение валового цезия $[5,6]$.

На концентрирование цезия соосаждением на неорганических коллекторах, в частности карбонате кальция и сульфате бария мешающее влияние оказывает хлорид натрия в концентрации свыше 30 г/дм ${ }^{3}$ [4].

Концентрирование соосаждением на гетерополисоединениях, например, на фосфорномолибденовой кислоте или вольфрамофосфате аммония требует значительных количеств коллектора, более 10 ммоль/дм ${ }^{3}$ и кроме, того на степень соосаждения мешающее влияние оказывают ионы натрия в концентрации более 0,1 моль/дм ${ }^{3}$. Процесс отделения осадков солей гетерополисоединений усложнен вследствие того, что частицы сорбента крайне плохо отстаиваются и фильтруются, центрифугирование затруднено ввиду больших объемов растворов [6].

Для сооосаждения цезия-137 при анализе пищевых продуктов используются ферроцианиды никеля или кобальта [1], при анализе морской воды - ферроцианид меди [2]. Однако, степень извлечения цезия-137 не превышала $92 \%$.

Цезий в растворах поваренной соли, рассолах и высокоминерализованных водах находится в связанной форме, преимущественно с гуминовыми и фульвокислотами, что затрудняет его количественное концентрирование сорбцией и соосаждением (табл.1) [1].

Таблица 1

Результаты определения цезия.

\begin{tabular}{|c|c|c|c|c|c|c|c|}
\hline \multirow[b]{2}{*}{$\begin{array}{l}\text { Объект } \\
\text { анализа }\end{array}$} & \multirow[b]{2}{*}{$\begin{array}{c}\text { Введено } \\
\text { Cs, } \\
\cdot 10^{-7} \%\end{array}$} & \multicolumn{6}{|c|}{ Найдено Cs · 10-7, \% / Sr(p=0,95, n=6) } \\
\hline & & $\begin{array}{c}\text { Без } \\
\text { обработки }\end{array}$ & $\begin{array}{c}\text { С кипячением } \\
\text { с } \\
\text { персульфатом } \\
\text { аммония в } \\
\text { кислой среде }\end{array}$ & $\begin{array}{c}\text { С УЗ } \\
\text { обработкой } \\
22 \text { кГц, } 7 \\
\text { Вт/см }{ }^{2}, 3 \\
\text { мин }\end{array}$ & $\begin{array}{c}\text { С УЗ } \\
\text { обработкой } \\
22 \text { кГц, } 2 \\
\text { Вт/см², } 2 \text { мин } \\
\text { в } \\
\text { присутствии } \\
\mathrm{H}_{2} \mathrm{O}_{2}\end{array}$ & $\begin{array}{c}\text { С УЗ } \\
\text { обработкой } \\
22 \text { кГц, } 7 \\
\mathrm{Bт} / \mathrm{cm}^{2}, 3 \\
\text { мин при } \\
\text { насыщении } \\
\text { пробы } \mathrm{CO}_{2}\end{array}$ & $\begin{array}{c}\text { С УЗ } \\
\text { обработкой } \\
22 \text { кГц, } 2 \\
\text { Вт/см², } 2 \text { мин } \\
\text { в } \\
\text { присутствии } \\
\mathrm{H}_{2} \mathrm{O}_{2} \text { при } \\
\text { насыщении и } \\
\text { пробы } \mathrm{CO}_{2} \\
\end{array}$ \\
\hline \multirow{2}{*}{$\begin{array}{c}\text { Поваренная } \\
\text { соль ГП } \\
\text { «Артемсоль» }\end{array}$} & 0 & - & - & - & - & - & - \\
\hline & 2,00 & $2,07 / 0,03$ & $1,76 / 0,09$ & $1,86 / 0,06$ & $1,90 / 0,05$ & $1,87 / 0,07$ & $2,06 / 0,05$ \\
\hline \multirow{2}{*}{$\begin{array}{c}\text { Поваренная } \\
\text { соль Генич. } \\
\text { солезавод }\end{array}$} & 0 & $4,26 / 0,03$ & $8,97 / 0,08$ & $9,26 / 0,05$ & $9,31 / 0,05$ & $4,29 / 0,06$ & $5,31 / 0,05$ \\
\hline & 2,00 & $6,11 / 0,04$ & $10,45 / 0,09$ & $11,19 / 0,06$ & $11,29 / 0,06$ & $6,19 / 0,06$ & $7,27 / 0,06$ \\
\hline \multirow{2}{*}{$\begin{array}{l}\text { Поваренная } \\
\text { соль Генич. } \\
\text { солезавод* }\end{array}$} & 0 & $4,26 / 0,03$ & $8,76 / 0,08$ & $4,35 / 0,05$ & $9,31 / 0,05$ & $4,29 / 0,06$ & $5,31 / 0,05$ \\
\hline & 2,00 & $6,11 / 0,04$ & $10,58 / 0,09$ & $6,29 / 0,06$ & $11,29 / 0,06$ & $6,19 / 0,06$ & $7,27 / 0,06$ \\
\hline \multirow{2}{*}{$\begin{array}{c}\text { Рассол, } \\
\text { Славянский } \\
\text { солезавод }\end{array}$} & 0 & $3,81 / 0,04$ & $9,43 / 0,09$ & $9,66 / 0,06$ & $9,68 / 0,06$ & $3,96 / 0,06$ & $5,76 / 0,06$ \\
\hline & 2,00 & $5,75 / 0,03$ & $11,55 / 0,08$ & $11,70 / 0,07$ & $11,73 / 0,07$ & $6,01 / 0,07$ & $7,88 / 0,07$ \\
\hline \multirow{2}{*}{$\begin{array}{c}\text { Вода, } \\
\text { Сиваш, } \\
\text { район Генич. } \\
\text { солезавода }\end{array}$} & 0 & $1,88 / 0,05$ & $6,04 / 0,09$ & $6,34 / 0,06$ & $6,46 / 0,06$ & $2,06 / 0,06$ & $2,76 / 0,06$ \\
\hline & 2,00 & $4,01 / 0,04$ & $7,85 / 0,08$ & $8,43 / 0,07$ & $8,59 / 0,07$ & $3,09 / 0,07$ & $4,81 / 0,07$ \\
\hline
\end{tabular}

* с радиопротектором

Для перевода металлов в ионные формы используется кипячение растворов проб в течение 40 мин с сильными окислителями $\left(\mathrm{H}_{2} \mathrm{SO}_{4}-\left(\mathrm{NH}_{4}\right)_{2} \mathrm{~S}_{2} \mathrm{O}_{8}, \quad \mathrm{HNO}_{3}, \quad \mathrm{H}_{2} \mathrm{SO}_{4}-\mathrm{KMnO}_{4}, \quad\right.$ что удлиняет и усложняет анализ, увеличивает риск загрязнения растворов проб примесями цезия из используемых реагентов [1].
При анализе поваренной соли для перевода соединений свинца, меди, кадмия, ртути, цинка и мышьяка в соосаждаемые формы и для интенсификации соосаждением используется воздействие ультразвука (У3), что способствует повышению экспрессности, чувствительности и улучшению метрологических характеристик анализа [1]. 


\begin{tabular}{|c|c|c|c|c|c|c|}
\hline Impact Factor: & $\begin{array}{l}\text { ISRA (India) } \\
\text { ISI (Dubai, UAI } \\
\text { GIF (Australia) } \\
\text { JIF }\end{array}$ & $\begin{array}{l}=1.344 \\
=0.829 \\
=0.564 \\
=1.500\end{array}$ & $\begin{array}{l}\text { SIS (USA) } \\
\text { PUHЦ (Russia } \\
\text { ESJI (KZ) } \\
\text { SJIF (Morocce }\end{array}$ & $\begin{array}{l}=0.912 \\
=0.179 \\
=1.042 \\
=2.031\end{array}$ & $\begin{array}{l}\text { ICV (Poland) } \\
\text { PIF (India) }\end{array}$ & $\begin{array}{l}=6.630 \\
=1.940\end{array}$ \\
\hline
\end{tabular}

Целью работы является исследование возможности использования воздействия УЗ для перевода соединений цезия в соосаждаемые формы, а также для интенсификации процессов концентрирования цезия.

Экспериментальная часть. Валовое содержание цезия определяли атомноэмиссионным методом в пламени «ацетиленвоздух» при длине волны 852 нм на спектрометре AAS-3 (Германия). Цезий-137 определяли на бета-радиометре Руб-01П (Россия) с детектором БДЖБ-06П (Россия). УЗ обработку растворов проводили с использованием модернизированного ультразвукового диспергатора УЗДН-1М с набором магнитострикционных излучателей, позволяющих вести обработку растворов частотой 15-47 кГц, интенсивностью от 0,5 до 25 $\mathrm{BT} / \mathrm{cm}^{2}$. Для отделения осадков от раствора использовали центрифугу Т-23 (6000 об/мин). Опыты проводились в реакторе с водяной рубашкой при температуре $(20 \pm 1){ }^{0} \mathrm{C}$. Применяли бидистиллированную воду и реактивы квалификации не ниже х.ч. Интенсивность УЗ определяли расчетным и экспериментальным методами [1].

Анализируемые растворы поваренной соли обрабатывали УЗ частотой 18-44 кГц, интенсивностью 4-15 Вт/см ${ }^{2}$ в течение времени 0,5-5,0 мин. В полученном растворе устанавливали содержание цезия атомноэмиссионным методом после выделения цезия соосаждением на гексацианоферрате двухвалентной меди [4]. Причем, для повышения чувствительности определения цезия, в анализируемый раствор вводили хлорид натрия до 30 г/дм ${ }^{3}$, согласно рекомендаций приведенных в [1].

Результаты и их обсуждение. В результате опытов установлено, что оптимальными параметрами УЗ являются: частота 18-44 кГц, интенсивность более $7 \mathrm{BT} / \mathrm{cm}^{2}$ в течение времени более 3 мин (табл.2).

Таблица 2

Влияние параметров ультразвука на степень разрушения органических соединений цезия.

\begin{tabular}{|c|c|c|c|c|c|}
\hline $\begin{array}{l}\text { Интенсивность } \\
\text { УЗ, Вт/см }\end{array}$ & $\begin{array}{l}\text { Степень } \\
\text { разрушения } \\
\text { орг. соед. Сs, } \%\end{array}$ & $\begin{array}{l}\text { Частота УГ, } \\
\text { кц }\end{array}$ & $\begin{array}{l}\text { Степень } \\
\text { разрушения } \\
\text { орг. соед. Сs, \% }\end{array}$ & $\begin{array}{l}\text { Время возд. У3, } \\
\text { мин. }\end{array}$ & $\begin{array}{l}\text { Степень } \\
\text { разрушения } \\
\text { орг. соед. Сs, \% }\end{array}$ \\
\hline 4 & 67 & 15 & 95 & 0,5 & 84 \\
\hline 5 & 85 & 18 & 98 & 1 & 93 \\
\hline 6 & 94 & 20 & 98 & 2 & 96 \\
\hline 7 & 98 & 44 & 98 & 3 & 99 \\
\hline 8 & 98 & 45 & 96 & 4 & 99 \\
\hline 9 & 98 & 47 & 94 & 5 & 99 \\
\hline
\end{tabular}

Однако, при анализе поваренной соли с радиопротектором (содержание $\mathrm{Fe}_{4}\left[\mathrm{Fe}(\mathrm{CN})_{6}\right]_{3}-$ $1 \%$ ), перевода цезия в соосаждаемые формы воздействием только одного УЗ, даже интенсивностью $15 \mathrm{BT} / \mathrm{cm}^{2}$ достичь не удается (табл.1). В связи с чем, изучено ведение процесса в присутствии окислителей. В качестве окислителей изучено действие азотной кислоты, перекиси водорода $(30 \%)$, смеси перекиси водорода и азотной кислоты $(1: 1)$ и смеси азотной и соляной кислот (1:3), рекомендуемых для интенсификации пробоподготовки воздействием микроволнового облучения [8]. Как следует из табл.3, положительный эффект наблюдался при ведении процесса в присутствии всех вышеприведенных окислителей.

Влияние окислителей на степень извлечения цезия.

Таблица 3

\begin{tabular}{|c|c|c|c|c|c|}
\hline \multirow{2}{*}{ Объект анализа } & \multicolumn{5}{|c|}{ Найдено Сs $10-7, \% / \mathrm{Sr}(\mathrm{p}=0,95, \mathrm{n}=6)$} \\
\cline { 2 - 6 } & Без окислит. & $\mathrm{HNO}_{3}$ & $\mathrm{H}_{2} \mathrm{O}_{2}$ & $\mathrm{HNO}_{3}+\mathrm{H}_{2} \mathrm{O}_{2}$ & $\mathrm{HNO}_{3}+\mathrm{HCI}$ \\
\hline Поваренная соль Генич. солезавод & $4,26 / 0,03$ & $9,29 / 0,05$ & $9,31 / 0,05$ & $9,39 / 0,06$ & $9,36 / 0,06$ \\
\hline Поваренная соль Генич. солезавод* & $4,26 / 0,03$ & $9,31 / 0,06$ & $9,31 / 0,05$ & $9,37 / 0,06$ & $9,35 / 0,06$ \\
\hline $\begin{array}{c}\text { Рассол, Славянский солезавод } \\
\text { Вода, Сиваш, район Генич. } \\
\text { солезавода }\end{array}$ & $3,81 / 0,04$ & $9,71 / 0,06$ & $9,68 / 0,06$ & $9,74 / 0,07$ & $9,70 / 0,07$ \\
\hline \begin{tabular}{c} 
* с радиопротектором \\
\hline
\end{tabular} & $1,88 / 0,05$ & $6,42 / 0,06$ & $6,46 / 0,06$ & $6,51 / 0,07$ & $6,44 / 0,07$ \\
\hline
\end{tabular}

ISPC Perspectives in science for 2016, 
При этом, для количественного извлечения цезия необходимо на 1 дм $^{3}$ раствора пробы не менее $10 \mathrm{~cm}^{3}$ азотной кислоты или $5 \mathrm{~cm}^{3}$ перекиси водорода или такое же количество смеси перекиси водорода и азотной кислоты или смеси азотной и соляной кислот. Таким образом, оптимальным является введение перекиси водорода. Использование воздействия УЗ в присутствии перекиси водорода позволяет количественно перевести цезий в соосаждаемые формы и улучшить метрологические характеристики анализа, при этом интенсивность УЗ может быть уменьшена с 7 до $2 \mathrm{BT} / \mathrm{cm}^{2}$ (табл.1).
В оптимальных условиях степень соосаждения цезия достигает $92 \%$ и ее не удается повысить увеличением количества коллектора и времени контакта осадка с раствором [4].

Для повышения степени соосаждения использовано воздействие УЗ. Параметры ультразвука: частота 20-44 кГц, интенсивность 2 $\mathrm{BT} / \mathrm{cm}^{2}$, время воздействия 30 с подбирались экспериментально (табл.4). При этом степень соосаждения повышается до 98-99 \%. Количество коллектора может быть уменьшено в 5 раз.

Влияние параметров ультразвука на степень соосаждения цезия.

Таблица 4

\begin{tabular}{|c|c|c|c|c|c|}
\hline $\begin{array}{l}\text { Интенсивность } \\
\text { У3, Вт/см }\end{array}$ & $\begin{array}{l}\text { Степень } \\
\text { соосаждения } \\
\text { Сs, \% }\end{array}$ & $\begin{array}{l}\text { Частота } \\
\text { кГц }\end{array}$ & $\begin{array}{l}\text { Степень } \\
\text { соосаждения } \\
\text { Сs, \% }\end{array}$ & $\begin{array}{l}\text { Время возд. У3, } \\
\text { с. }\end{array}$ & $\begin{array}{l}\text { Степень } \\
\text { соосаждения } \\
\text { Сs, \% }\end{array}$ \\
\hline 0,5 & 36 & 15 & 80 & 10 & 76 \\
\hline 1 & 88 & 18 & 92 & 15 & 80 \\
\hline 2 & 98 & 20 & 99 & 20 & 83 \\
\hline 4 & 98 & 44 & 99 & 25 & 90 \\
\hline 5 & 99 & 45 & 90 & 30 & 98 \\
\hline 6 & 98 & 47 & 87 & 35 & 99 \\
\hline
\end{tabular}

Для установления определяющего фактора воздействия У3 использовали ведение процесса в условиях невозможности протекания звукохимических реакций (насыщение пробы $\left.\mathrm{CO}_{2}\right)$ при постоянной температуре [7]. В результате опытов установлено, при переводе цезия в соосаждаемые формы определяющим фактором интенсифицирующего действия УЗ является протекание звукохимических реакций, a при интенсификации концентрирования соосаждением - перемешивающее и диспергирующее действие УЗ (табл.1).

Таким образом, установлено, что применение УЗ пробоподготовки при определении цезия в высокоминерализованных вода, рассолах и поваренной соли позволяет повысить экспрессность, снизить предел обнаружения и улучшить метрологические характеристики анализа.

Разработана методика определения цезия и цезия-137 в высокоминерализованных водах, рассолах и поваренной соли.

Методика определения ичезия и ичезия-137 в высокоминерализованных водах, рассолах $u$ поваренной соли.

Навеску поваренной соли 100,00 г растворяют в бидистиллированной воде и доводят обьем раствора до $1000 \mathrm{~cm}^{3}$ (при анализе рассолов приливают количество рассола, содержащее 100 г хлорида нат-рия, а при анализе высокоминерализованных вод берут $1000 \mathrm{~cm}^{3}$ пробы воды), приливают $5 \mathrm{~cm}^{3}$ перекиси водорода (30 \%). Опускают магнитострикционный излучатель и воздействуют УЗ частотой 22 кГц, интенсивностью $2 \mathrm{BT} / \mathrm{cm}^{2}$ в течение 3 мин. Приливают $1 \mathrm{~cm}^{3}$ азотной кислоты (5 моль/дм $\left.{ }^{3}\right), 2$ см3 раствора меди азотнокислой $\left(2\right.$ моль/дм $\left.{ }^{3}\right), 3 \mathrm{~cm}^{3}$ раствора ферроцианида калия $\left(2\right.$ моль/дм $\left.{ }^{3}\right)$. Опускают магнитострикционный излучатель и воздействуют УЗ частотой 22 кГц, интенсивностью 2 Вт/см ${ }^{2}$ в течение 30 с. Осадок от раствора отделяют сифонированием и центрифугированием. Осадок высушивают при температуре $50 \quad{ }^{0} \mathrm{C}$,после охлаждения до комнатной температуры взвешивают, переносят в кювету бета-радиометра и определяют активность при времени измерения количества импульсов в течение 100 с. Для определения валового содержания цезия осадок растворяют в 6 см3 соляной кислоты $(1: 1)$ при нагревании, приливают 1,5 $\mathrm{cm}^{3}$ раствора хлорида натрия и разбавляют бидистиллированной водой до 10 $\mathrm{cm}^{3}$. Определение ведут атомно-эмиссионным методом при длине волны 852 нм в пламени ацетилен-воздух.

Предел обнаружения цезия - $2 \cdot 10^{-8} \%$, цезия$137-1 \cdot 10^{-13} \mathrm{Ku} /$ кг.

ISPC Perspectives in science for $\mathbf{2 0 1 6}$, 
Правильность определения цезия проверяли методом добавок на растворах проб поваренной соли, рассолах и высокоминерализованных водах (табл.1).
Правильность определения цезия -137 проверяли, сравнивая полученные результаты с результатами гамма-спектрального анализа (табл. 5).

Таблица 5

Результаты определения цезия-137 разработанным и гамма-спектральным методами.

\begin{tabular}{|c|c|c|}
\hline \multirow{2}{*}{ Объект анализа } & \multicolumn{2}{|c|}{ Найдено цезия-137, Бк/кг(n=6, $\mathrm{p}=0,95)$} \\
\cline { 2 - 3 } & Гамма-спектральным метод. & Разработанным метод. \\
\hline Поваренная соль ГП «Артемсоль» & $4,59 \pm 0,56$ & $4,81 \pm 0,33$ \\
\hline Поваренная соль Генич. солезавод & $12,95 \pm 1,63$ & $13,51 \pm 0,93$ \\
\hline Рассол, Славянский солезавод & $23,05 \pm 3,96$ & $42,57 \pm 1,78$ \\
\hline Вода, Сиваш, район Генич. солезавода & $43,11 \pm 5,25$ & 42,92 \\
\hline
\end{tabular}

Выводы. Изучено применение УЗ при определении цезия в высокоминерализованных водах, рассолах и поваренной соли: для перевода соединений цезия в соосаждаемые формы и для интенсификации концентрирования соосаждением на гексацианоферрате двухвалентной меди. Экспериментально установлено, что определяющим фактором интенсифицирующего воздействия УЗ при переводе цезия в соосаждаемые формы является протекание звукохимических реакций, а при интенсификации концентрирования соосаждением - перемешивающее и диспергирующее действие УЗ. Разработана экспрессная методика определения цезия и цезия - 137, основанная на соосаждении цезия на гексацианоферрате двухвалентной меди с ультразвуковой интенсификацией процесса. В полученном концентрате цезий определяли атомно-эмиссионным методом при длине волны 852 нм в пламени ацетилен-воздух, а цезий-137с использованием бета-радиометра. Предел обнаружения цезия - $2 \cdot 10^{-8} \%$, цезия- $137-1 \cdot 10$ ${ }^{13} \mathrm{Ku} / \mathrm{\kappa}$.

\section{References:}

1. Baklanov OM, Avdeenko AP, Chmilenko FO, Baklanova LV (2011) Analitichna khimiya kukhonnoï soli ta rozsoliv: MonografiyaKramators'k: Vid. DDMA, 2011. - 282 p.

2. (2013) GOST 32161-2013 Produkty pishchevye. Metod opredeleniya soderzhaniya tseziya Cs-137.

3. Epov Vladimir N, Lariviere Dominic, Reiber Karen M, Evans Douglas R, Cornett Jack R (2004) Extraction and determination of Cs in natural waters by ICP-MS after ion exchange separation // Anal. Atom. Spectrom. N 9, 2004, t.19, pp.1225-1229.

4. Plyushchev VE, Stepin BD (1975) Analiticheskaya khimiya rubidiya i tseziya.Moscow: Nauka, 1975. - 224 p.
5. Remez VP (2015) Kontsentrirovanie radiotseziya sorbentom ANFEZh // Sorbtsionnye i khromatograficheskie protsessy.2015.- t.9, Vyp. 6.- pp. 783-788.

6. Plyushchev VE, Stepin BD (2014) Khimiya i tekhnologiya soedineniy litiya, rubidiya i tseziya.- Moscow: Khimiya, 2014.- 414 p.

7. Margulis MA (1986) Zvukokhimicheskie reaktsii i sonolyuminestsentsiya. - Moscow: Khimiya, 1986. - 288 p.

8. Karpov YA (2012) Metody probootbora i probopodgotovki.- Moscow: BINOM, 2012.243 p. 